\title{
EEN TWEETAL BIJDRAGEN TOT DE KENNIS VAN HALMAHERA.
}

Het groote eiland Halmahera, naar het vroegere rijkje Djailolo veelal Gilolo geheeten, behoort, hoezeer gelegen in de onmiddellijke nabijheid der zoo lang reeds door de Europeanen overheerde Specerij-Eilanden, nog steeds onder die deelen van Neerlandsch-Indië, met wier aardrijkskundige gesteldheid en bevolking wij zeer onvolledig bekend zijn. Al wat in deze eeuw over dit eiland het licht zag, bepaalt zich bijna uitsluitend tot het aan het Ternataansche rijk onderworpen noordelijk schiereiland.

Daaronder behoort vooreerst een belangrijk opstel vau wijlen mijn vriend T. J. Willer: De Halfoeren van Noord-Halmahera, dat met gelijksoortige opstellen over de Alfoeren van NoordCeram en het eiland Boeroe geplaatst werd in het te Batavia uitgegeven tijdschrift Indisch Archief en daarna weder is opgenomen in het door Willer en den oud-raad van Indië Jhr. Cornets de Groot van Kraaijenburg vervaardigde verzamelwerk: Het eiland Boeroe en de kolonisatie in Nederlandsch-Indië. Willer verzelde in 1847 den commissaris Weddik op diens tocht door den Molukschen Archipel, waarbij hem een onderzoek was opgedragen naar de instellingen der oorspronkelijke bevolking van dit uitgestrekte gouvernement. Volijverig navorscher - ja pluizer - als hij was, heeft hij ons over de zeden en gewoonten der Alfoeren van Noord-Halmahera veel wetenswaardigs medegedeeld, terwijl hij aan dit ethnografisch onderzoek eene beknopte aardrijkskundige beschrijving van het noordelijk schiereiland met de indeeling in tien distrikten deed voorafgaan.

Uitvoeriger inlichting over de eigenlijke plaatsbeschrijving van Noord-Halmahera vindt men in de Aanleekeningen gehou3e Volgr. VII. 
den op eene reis aan de noord. en westkust van Halmaliera, geplaatst in het Tijdschrift voor Ned. Indië, 1856, D. II, blz. 209-228, waarin van de hier hoofdzakelijk alleen behandelde distrikten Djailolo en Sahoe op de west-, Galela, Tabello en Kaoe op de oostkust de namen der verschillende negorijen opgegeven en een aantal topografische bijzonderheden medegedeeld worden. Ongelukkig verscheen dit opstel in het tweede tijdvak van het Tïdschrift voor Ned. Indië, dat men voor de daarin vervatte wetenschappelijke mededeelingen de oncritische periode zou kunnen noemen. De aan het opstel gegeven titel is reeds slecht gekozen. Wat toch moet men onder de noordkust van Halmahera verstaan, vooral hier, waar alleen van het noordelijk schiereiland sprake is? Vele eigennamen zijn door drukfouten bijna onkenbaar. De naam van den schrijver wordt niet medegedeeld, evenmin het jaar, waarin de reis plaats had. Zou de redactie dit gelaten hebben, omdat de regeering destijds onze kostbare Indische bezittingen zooveel mogelijk achter mat glas verborg? Ik kan dit niet denken. De nimmer door het kultuurstelsel bezochte Molukken behoorden toch tot die buitenbezittingen, waarvoor men het licht niet schuwde. Bovendien leest men op blz. 224, dat het afloopen van Bawean door Tabelloreesche zeeroovers een jaar te voren geschiedde, waaruit blijkt, dat deze reis omstreeks 1852 moet hebben plaats gehad. De reiziger eindelijk, die hier en daar uitvoerig de bevolkingsstatistieken opgeeft, moet een ambtenaar geweest zijn, zoodat de regeering, wanneer zij dit begeerde, zijn naam gemakkelijk had kunnen uitvorschen. Dit ontbreken van den naam des schrijvers is dus mijns inziens geen reden, om met den heer de Hollander (Land en Volkenk. van Ned. Indiè, D. II, bl. 355) aan dit opstel minder vertrouwen te schenken; alleen moet men het wegens de vele fouten in de eigennamen met voorzichtigheid en critiek gebruiken.

Eenige jaren later werd Halmahera door twee natuuronderzoekers bezocht, den beroemden Wallace en den te vroeg overleden Dr. Bernstein. De eerste bracht in 1858 enkele korte bezoeken aan de door de onmiddellijke nabijheid van Ternate het meest bekende plaatsen Dodinga, Djailolo en Sahoe, terwijl hij in 1860 op zijn terugreis van Waigeoe ook Gane op het onder Ternataansch beheer staande Zuid-Halmahera aandeed. Hoeveel Wallace ook tot de vermeerdering van onze kennis der fauna van Halmahera hebbe bijgedragen, voor de eigenlijke 
land- en volkenkunde van dit eiland geeft hij weinig nieuws, terwijl zijne ethnografische beschouwingen over de toenadering der bevolking van Halmahera tot de Papoes ook mijns inziens, evenals reeds Prof. Veth in zijne vertaling van Wallace's werk opmerkt, ten hoogste nadere bevestiging vereischen.

Van veel grooter gewicht zijn Bernsteins geografische onderzoekingen op Halmahera, waarover ongelukkig van zijne reizen in 1861,1862 en 1863 alleen zijne voorloopige mededeelingen geplaatst rijn in het Tijdschrift van het Bataviaasch Genootschap, D. XIV, terwijl van zijn laatste reis in 1864 door zijn overlijden slechts zeer korte op reis gemaakte aanteekeningen het licht zagen (in genoemd tijdschrift D. XVII). Ware hij in het leven gespaard gebleven, ongetwijfeld had zijne te verwachten uitvoerige reisbeschrijving veel meer geleverd. Van Mei-October 1861 onderzocht hij vooral het distrikt Galela, waar hij den vuurberg Goenong Api of Tolo en den uitgebranden vulkaan Mamoeia beklom, voorts de eilanden Rau en Morotai. Van November 1862 tot April van het volgende jaar bezocht hij de distrikten Kaoe en Tabello en wijdde een meer nauwkeurig onderzoek aan het tot dusver meestal voor onbewoond gehouden Morotai. Op zijne groote reis naar de Papoesche Eilanden in 1863 ging hij eerst van Pajahe over land naar Weda en verder te scheep langs de zuidkust van het ruidoostelijk schiereiland; op zijn terugtocht nam hij eerst denzelfden weg, maar zeilde nu Zuid-Halmahera om en gaf tevens eenige berichten over het zuidelijke en centrale gedeelte der westkust. Ook op zijn tweede reis naar de Papoesche Eilanden in 1864 volgde hij dezen weg, waarbij hij over de zuidkust van het zuidoostelijk schiereiland nieuwe bijzonderheden mededeelde. Op deze beide laatste reizen bezocht Bernstein evenwel alleen in het voorbijvaren enkele plaatsen van Zuid- en Oost-Halmahera, zoodat ook hij eigenlijk alleen het noordelijk schiereiland grondig onderzocht.

Behalve het weinige, dat Wallace en Bernstein over de distrikten Gane, Weda en Patani mededeelen, bepaalt zich dus onze kennis van Halmahera tot het noordelijk schiereiland, zooals ook uitdrukkelijk door Prof. de Hollander (Land en Volk. II, bl. 352) wordt opgemerkt. Reeds voor jaren verlangde het Instituut in de door het bestuur uitgeschreven vragen eene beschrijving der drie overige schiereilanden, vooral van TidoreeschHalmahera, waaronder men de beide oostelijke schiereilanden met het centrale gedeelte des eilands verstaan moet. Te vreemder 
mocht deze geheele onbekendheid met dit deel van Halmahera heeten, daar de gouverneur-generaal van der Capellen in 1824 op zijne inspectie-reis door de Molukken een post vestigde in het omstreeks het begin dezer eeuw veel door vreemde walvischvaarders bezochte Bitjoli, welke vestiging eerst eenige jaren daarna onder de bezuinigingsmaatregelen van du Bus weder werd ingetrokken. Toen dau ook onze tegenwoordige voorzitter, de heer Bleeker, onder het opstellen van zijn belangrijk werk over de Molukken bemerkte, dat wij van drie schiereilanden van Halmahera nauwelijks den juisten omtrek kennen, zocht hij in de gouvernements-archieven te Batavia naar de dienstverslagen over deze vestiging te Bitjoli, maar vond die tot zijn leedwezen niet. (Reis door de Minahassa en den Mo. lukschen Archipel, 1. I, bl, 258).

Toch was de later als resident van Manado overleden Joan Pieter Cornelis Cambier, dien van der Capellen onder den titel van assistent-resident tot gecommitteerde voor Tidoreesch-Halmahera benoemd had, de man niet, om geen behoorlijk rapport over nijue verrichtingen te geven. Het bestaan van zulk een verslag vermoedde ik het eerst in 1868 , toen de oud-gouverneur der Molukken Jhr. F. V. A. Ridder de Stuers aan het Instituut eenige beknopte asuteekeningen over dit gouvernement ten geschenke gaf. Daarin toch vond ik onder anderen eene indeeling van Tidoreeseh-Halmahera in distrikten met meer andere byzonderheden, blijkbaar uittreksels uit een uitvoerig dienstrapport. Een onderzoek naar dit stuk zelf bij den welwillenden gever leidde aanvankelijk tot geen resultaat. Eerst eenigen tijd darna ontdekte ik op de auctie van wijlen den heer Lauts het oorspronkelijke rapport van Cambier over Tidoreesch-Halmahera, dat met andere handschriften over de Molukken op mijn voorstel voor de bibliotheek van het Instituut werd aangekocht.

Het versiag van Cambier, hoe belangrijk ook wegens onze geheele onbekendheid met Tidoreesch-Halmahera, handelt evenwel over een tijdvak, dat nu reeds bijna een halve eeuw achter ons ligt en waarin deze gewesteu door volksverhuizingen bijna ontrolkt waren. Daar nu sedert deze streken, hoewel zij weder geheel buiten den rechtstreekschen invloed van het Nederlandsch gezag staan, toch na het eindigen der voortdurende onlusten, die het rijk van Tidore van omstreeks 1790 tot 1820 verwoestten, tot eenige grootere rust en welvaart gekomen zijn, 
was het na den ankoop van dit handschrift eerst wenschelijk af te wachten, wat over Bernsteins onderzoekingen op Halmahera het licht zou zien en voorts na te gaan, wat in oude documenten nog belangrijks over dit eiland te vinden was.

In de eerste plaats kwam daarvoor eene betere kaart van Halmahera in aanmerking. Sedert het herstel van het Nederlandsch gezag in den Indischen Archipel is ons beheer aanzienlijk uitgebreid over en daardoor ook onze kennis aanmerkelijk vermeerderd van Borneo en Sumatra, van Zuid-Celebes en de Minahassa, maar van vele deelen van het uitgestrekte gouvernement der Molukken weten wij thans veel minder dan onze voorvaderen in de dagen der Compagnie. Het duidelijkste blijkt dit bij vergelijking onzer nieuwe kaarten, zooals die in Melvill's Atlas en Gregory's kaart der Molukken met de uitvoerige kaarten uit den ouden atlas in handschrift, die de kamer van Amsterdam in het begin der vorige eeuw door den bekwamen kaartenmaker Isaäc de Graafl deed vervaardigen en thans op het Rijksarchief bewaard worden. Toen dan ook het Instituut

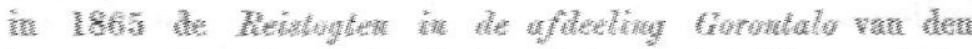

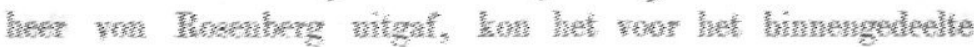

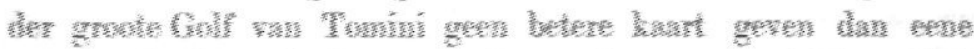

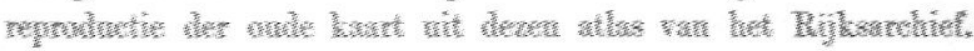

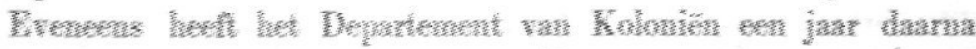

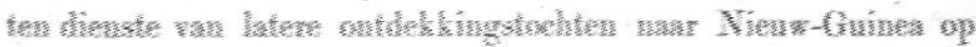

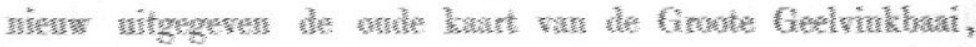

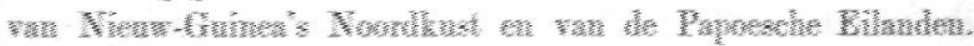

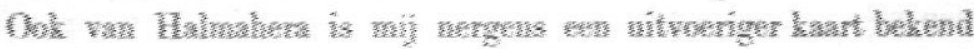

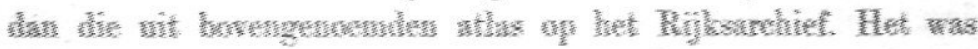

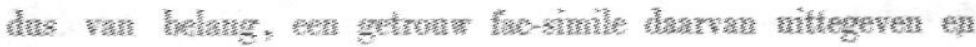

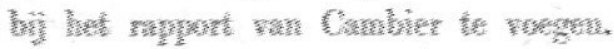

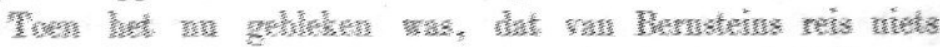

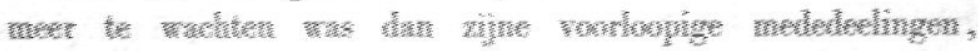

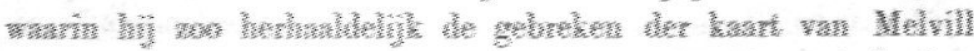

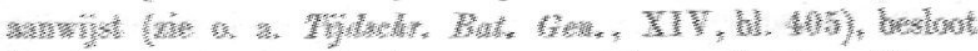

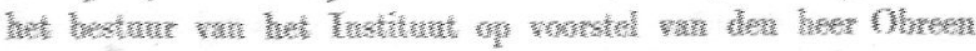

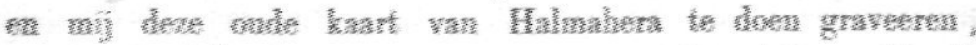

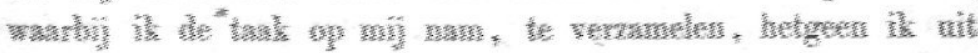

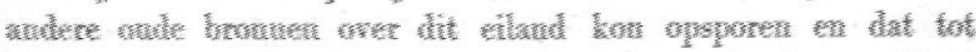

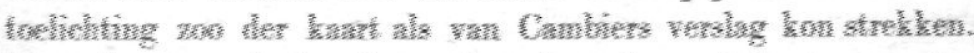

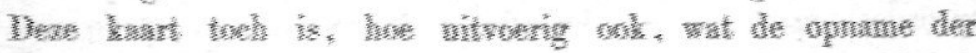

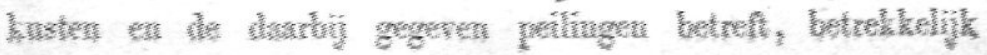


schaars voorzien van inlandsche plaatsnamen. Het was dus wenschelijk, deze zeekaart te vergelijken met eene in 1720 vervaardigde landkaart der limietscheiding tusschen het Ternataansch en Tidoreesch gebied op Noord-Halmahera uit de verzameling van het Rijksarchief en op te zoeken, wat men in oude documenten der Compagnie en in Spaansche of Portugeesche werken over dit eiland vinden kon. De Portugeezen en vooral de Spanjaarden waren, toch met het thans zoo onbekende Halmahera, door hen meestal Batoe China, Moro of Gilolo genoemd, betrekkelijk beter bekend, dan met menig ander deel van den Indischen Archipel. Zoo vindt men reeds op oude Portugeesche kaarten, waar Manado en Makassar nog als kleine afzonderlijke eilandjes zijn voorgesteld, de eigenaardige vorm van Gilolo met zijne vier schiereilanden behoorlijk aangegeven en bevat de door Navarrete uitgegeven, maar ongelukkig onvoltooid gebleven reisverzameling in het laatste deel het beknopt verslag, hoe dit eiland reeds omstreeks 1525 door een Spaanschen stuurman werd omzeild.

Hoewel ik nu voor dit doel veel had bijeenverzameld, wat zoo voor de plaatsbeschrijving als de oudere geschiedeuis van Halmahera niet onbelangrijk mocht heeten, was het mij nog niet gelukt, dit tot een voor mij zelf bevredigend geheel te vereenigen, toen ik van dezen arbeid werd afgeroepen door de ontvangst van het reeds lang uit Indië verwachte handschrift van den heer von Rosenberg over zijne laatste reizen in de Geelvinkbaai. Ik had den schrijver beloofd, zijn arbeid voor de pers na te zien en waar mij zulks noodig voorkwam, daarbij aardrijkskundige aanteekeningen te voegeu. Dit moest voorgaan, opdat deze belangrijke reisbeschrijving zoo spoedig mogelijk het licht kan zien, hetgeen te wenschelijker is, nu men in het buitenland meer en meer op Nieuw-Guinea de aandacht vestigt, om ook op wetenschappelijk gebied Nederlands prioriteit in deze streken te handhaven, voorts omdat juist nu in Neerlandsch-Indië telkens van nieuwe expeditiën naar deze terra incognita sprake is. Om nu de uitgave der reeds gegraveerde kaart niet langer te vertragen, ziet die thans het licht met het rapport van Cambier en deze beknopte toelichting over het gewicht en de herkomst dezer twee te lang reeds aan het publiek onthouden documenten. Later hoop $\mathrm{ik}$ gelegenheid te vinden tot verdere mededeelingen over de historische topografie van Halmahera en dan of in een af̣zonderlijk opstel voor goed een einde te 
maken aan de tot juist verstand van de geschiedeuis der Molukken zoo hinderlijke verwarring tusschen Portugeezen en Spanjaarden, die men vooral in den laatsten tijd telkens bij onze voornaamste schrijvers over Indische geschiedenis aantreft. ${ }^{1}$

Tot wering van verder misverstand voorloopig slechts deze opmerking. Na Verhaghens verovering van Ambon en Tidore in 1605 zijn de Portugeezen voor altijd uit de Molukken verdreven. Sedert voerden de Nederlanders daar en in NoordCelebes gedurende meer dan een halve eeuw een onafgebroken wedstrijd, niet met de Portugeezen uit Malakka, maar met de Spanjaardeu uit Manilla, een strijd, die zich telkens ver buiten de grenzen van het tegenwoordig Neerlandsch-Indië tot naar Mindanau en de Philippijnen, ja tot naar Formosa en Cambodja uitbreidde.

's Hage, 28 Sept. 1872.

Robidé VAN DER Aa.

1 Wallace en andere schrijvers vermelden op Halmahera dikwijls oude Portugeesche forten. Zonder nader onderzoek zou ik durven beweren, dat dit overblijfsels van Spaansche forten zijn. Prof. Veth laat dit in zijne zoo belangrijke aanteekeningen op Wallace's Insulinde onveranderd, en waar hij terecht het onderscheid tusschen Gammalamme en Maleyo, de oude en nieuwe hoofdplaats van Ternate, niteenzet, beweert deze uitstekende geschiedvorscher in een onbewaakt oogenblik, dat Gammalamme nog tot na den Munsterschen vrede aan de Portugeezen behoorde. Ook de heer de Jonge noemt in zijn in vele opzichten zoo uitmuntende werk over de opkomst van ons gezag in Indië denzelfden vlootvoogd, hetzelfde fort of schip naar willekeur Portugeesch of Spaansch, als waren dit twee synoniemen, die men, toen Portugal en Spanje onder één koning stonden, tot stijlafwisseling door elkaar kan gebruiken. Zelfs in die dagen was het beheer over beide rijken en vooral dat over hunne koloniën scherp afgescheiden. Waar beide natiën in Indië tot afwering van den gemeenschappelijken vijand te zamen ageerden, mislukten deze expeditiën gewoonlijk door hun onderlingen naijver, even als de gecombineerde scheepstochten der Engelschen en Nederlanders in de Oostersche zeeën. Op zeldzame uitzonderingen na houden de oude stukken, ook Valentijn, van Kampen en Lauts, de Portngeezen en Castilianen goed uit elkaar. De verwarring dagteekent eerst van den lateren tijd en heerscht weder zoo sterk in het onlangs verschenen werk van den heer Meinsma, dat het meer dan tijd wordt, er eens ernstig tegen te waarschuwen. 